\title{
Evaluation of EGFR as a prognostic and diagnostic marker for head and neck squamous cell carcinoma patients
}

\author{
HANA POLANSKA ${ }^{1,2^{*}}$, MARTINA RAUDENSKA ${ }^{1,2^{*}}$, KRISTYNA HUDCOVÁ $^{1,2}$, \\ JAROMIR GUMULEC $^{1,2}$, MARKETA SVOBODOVA ${ }^{1,2}$, ZBYNEK HEGER $^{3}$, \\ MICHAELA FOJTU $^{1,4}$, HANA BINKOVA ${ }^{5}$, ZUZANA HORAKOVA ${ }^{5}$, ROM KOSTRICA ${ }^{5}$, \\ VOJTECH ADAM $^{1,3}$, RENE KIZEK ${ }^{1,3}$ and MICHAL MASARIK ${ }^{1,2}$ \\ ${ }^{1}$ Central European Institute of Technology, Brno University of Technology, CZ-616 00 Brno; \\ ${ }^{2}$ Department of Pathological Physiology, Faculty of Medicine, Masaryk University, CZ-625 00 Brno; \\ ${ }^{3}$ Department of Chemistry and Biochemistry, Mendel University in Brno, CZ-613 00 Brno; \\ ${ }^{4}$ Department of Physiology, Faculty of Medicine, Masaryk University, CZ-625 00 Brno; \\ ${ }^{5}$ Department of Otorhinolaryngology and Head and Neck Surgery, \\ St. Anne's Faculty Hospital, CZ-656 91 Brno, Czech Republic
}

Received October 23, 2015; Accepted May 26, 2016

DOI: $10.3892 / 01.2016 .4896$

\begin{abstract}
Approximately 90\% of all head and neck tumors are squamous cell carcinomas. The overall survival of patients with head and neck squamous cell carcinoma (HNSCC) is low $(\leq 50 \%)$. A non-invasive marker of disease progression is sorely required. The present study focused on the plasmatic levels of epidermal growth factor receptor (EGFR) in HNSCC patients $(\mathrm{N}=92)$ compared with healthy $(\mathrm{N}=29)$ and diabetic [type 2 diabetes mellitus (T2DM); N=26] controls. Enzymelinked immunosorbent assay using antibodies against the extracellular region of EGFR (L25-S645) was performed. No significant changes were observed between diabetic and healthy controls. However, there were significantly higher EGFR plasma levels in HNSCC patients compared with both control groups ( $\mathrm{P}=0.001$ and 0.005 , respectively). Receiver operating characteristic curve analysis identified a sensitivity of $76.09 \%$, a specificity of $67.27 \%$ and an area under curve of 0.727 for this comparison. No significant association was observed between EGFR plasma levels and tumor stage, tumor grade, lymph node or distant metastasis occurrence, smoking habit or hypertension. However, the presence of human papillomavirus infection and T2DM in HNSCC patients had borderline effect on the plasma EGFR levels. Survival analysis
\end{abstract}

Correspondence to: $\mathrm{Dr}$ Michal Masarik, Department of Pathological Physiology, Faculty of Medicine, Masaryk University, Kamenice 5, CZ-625 00 Brno, Czech Republic

E-mail:masarik@med.muni.cz

${ }^{*}$ Contributed equally

Key words: spinocellular cancer, biomarker, EGFR, head and neck tumors, plasma, diagnosis revealed no significant influence of plasmatic EGFR levels on the overall and disease-specific survival of HNSCC patients. In conclusion, EGFR plasma levels appear to be a relatively promising diagnostic, but poor prognostic, HNSCC marker.

\section{Introduction}

Epidermal growth factor receptor (EGFR), also known as ErbB1, is a $170-\mathrm{kDa}$ transmembrane glycoprotein belonging to the ErbB/human epidermal growth factor receptor family of receptor tyrosine kinases (1-3). EGFR is composed of an extracellular highly glycosylated ligand-binding domain (ECD) comprising amino acids 1-621, a hydrophobic transmembrane domain (amino acids 622-644) and an intracellular domain with tyrosine kinase activity for signal transduction (amino acids 645-1,186) (Fig. 1) (1-3). Upon binding of a ligand-like amphiregulin, EGF or transforming growth factor $\alpha$ (TGF $\alpha$ ) undergoes a conformational change by homo-dimerization or hetero-dimerization with another member of the erbB family, followed by auto-phosphorylation $(4,5)$. This results in tyrosine kinase activation and triggering of signaling cascades. Activation of EGFR leads to the activation of intracellular signaling pathways that regulate cell proliferation, invasion, angiogenesis and metastasis $(4,5)$. EGFR has been selected as a target of anticancer treatments due to its critical roles in cell survival and proliferation (6). EGFR is a strong prognostic marker in head and neck, ovarian and cervical cancer (7-9). EGFR expression has been associated with a higher proliferative index, advanced tumor stage and increased tumor angiogenesis in HNSCC (9). Overexpression of EGFR and TGF $\alpha$ significantly predicted a shorter disease-free and overall survival (9). EGFR activation also resulted into increased cell invasiveness and motility (10) via the induction of epithelial-to-mesenchymal transition $(11,12)$. Furthermore, EGFR can interact with the receptor cluster of differentiation 44 , resulting in a migratory cell phenotype (13). In addition to membrane-bound EGFR, tumor 
cells express soluble EGFR proteins that can be produced by alternative messenger (m)RNA splicing events, aberrant translocation or disintegration of circulating tumour cells $(14,15)$. Another 110-kDa soluble EGFR isoform, termed proteolytic isoform-soluble (PI-s)EGFR, is disengaged by proteolytic cleavage partially caused by metalloproteases $(16,17)$. Sanderson et al (18) have also reported two soluble isoforms of EGFR (150 and 100-kDa) within exosomes.

The present study focused on plasmatic EGFR levels of HNSCC patients, which were analyzed by enzyme-linked immunosorbent assay (ELISA) using anti-EGFR antibodies raised against the L25-S645 region of full-length EGFR. Notably, information about binding sites of ELISA antibodies are often not provided in the literature, despite that it could be very important for interpretation of the results obtained. Blood markers are less invasive than tissue biopsies, and sample collection can be repeated, which enables real-time monitoring of disease progression and treatment response in patients. As a control group, a gender- and age-matched healthy cohort, and a gender- and age-matched cohort of patients with type 2 diabetes mellitus (T2DM), were used. The T2DM group was included because a proportion of the present HNSCC patients also exhibited T2DM, and certain studies have shown that diabetes suppresses the expression of EGFR (19). Since EGFR is affected by both female estrogen receptors $(20,21)$ and male androgen receptors (22), EGFR may be a potential mediator of gender-related differences in HNSCC. Based on these facts, female HNSCC patients were excluded from the current study.

\section{Materials and methods}

Samples preparation. The present study was approved by the ethical committee of St. Anne's Faculty Hospital (Brno, Czech Republic). All surgical tissue samples were obtained from male HNSCC patients treated at St. Anne's Faculty Hospital between April 2013 and June 2015 upon providing informed consent. Histologically verified primary HNSCC carcinoma tissues were collected (92 samples). The tissue material harvested at surgery was placed into RNAlater ${ }^{\circledR}$ solution for RNA stabilization and storage (Ambion; Thermo Fisher Scientific, Inc., Waltham, MA, USA). The material was maintained cold, and RNA was isolated within $24 \mathrm{~h}$. Additional information about the patients and controls is presented in Table I.

Blood samples from HNSCC patients and healthy $(\mathrm{N}=29)$ and T2DM ( $\mathrm{N}=26)$ controls were obtained by venipuncture, and $5 \mathrm{ml}$ was placed into an S-Monovette ${ }^{\circledR} 4.9 \mathrm{ml}$, K3EDTA test-tube (Sarstedt AG \& Co., Nümbrecht, Germany) for plasma preparation. The blood samples were centrifuged at $1,200 \mathrm{x}$ g at $4^{\circ} \mathrm{C}$ for $10 \mathrm{~min}$ within $60 \mathrm{~min}$ of collection. Plasma was aliquoted and stored at $-80^{\circ} \mathrm{C}$ until analysis.

ELISA analysis. Plasma levels of EGFR were determined with a commercial ELISA kit (RayBiotech, Inc., Norcross, GA, USA) according to the manufacturer's protocol. The ELISA was designed to detect human EGFR in plasma or serum with a detection limit of $4 \mathrm{pg} / \mathrm{ml}$, a $10 \%$ intra-assay varaibility and a $12 \%$ inter-assay variability, as described in the manufacturer's instructions. For the assay, plasma samples were diluted 100 -fold, and evaluated with anti-EGFR antibodies raised against the L25-S645 region of EGFR.
Table I. Characterization of patients and controls.

\begin{tabular}{lccc}
\hline Group & Factor & $\begin{array}{c}\text { Number } \\
\text { of cases }\end{array}$ & $\begin{array}{c}\text { Age, years } \\
\text { (range) }\end{array}$ \\
\hline HNSCC patients & & 92 & $62.90(44-89)$ \\
& TNM T1-2 & 39 & $62.42(44-89)$ \\
& TNM T3-4 & 52 & $63.17(47-87)$ \\
& TNM N0 & 42 & $65.04(44-89)$ \\
& TNM N1 & 49 & $61.26(44-77)$ \\
& TNM M0 & 86 & $62.86(44-89)$ \\
& TNM M1 & 5 & $62.12(55-71)$ \\
& Grade 1 & 6 & $63.46(53-79)$ \\
& Grade 2 & 50 & $63.26(44-89)$ \\
& Grade 3 & 32 & $61.49(47-75)$ \\
& Non-smoker & 28 & $66.99(46-89)$ \\
Healthy controls & Smoker & 59 & $62.01(44-78)$ \\
Diabetic controls & & 29 & $64.38(54-69)$ \\
& & 26 & $56.73(50-83)$
\end{tabular}

TNM, tumor-node-metastasis; HNSCC, head and neck squamous cell carcinoma.

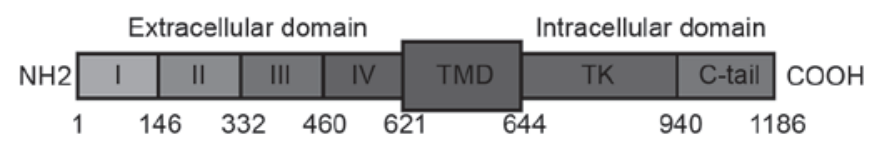

Figure 1. Schematic representation of EGFR protein (170-kDa). EGFR is composed of an extracellular highly glycosylated ligand-binding domain (comprising amino acids 1-621; exons 1-15), a hydrophobic transmembrane domain (amino acids 622-644; exons 15-17) and an intracellular domain with tyrosine kinase activity for signal transduction (amino acids 645-1,186; exons 18-28). I-IV denote subdomains of the extracellular domain. The figure was adapted from Albitar et al (1). TMD, transmembrane domain; TK, tyrosine kinase; EGFR, epidermal growth factor receptor.

RNA isolation and reverse transcription (RT). TriPure Isolation reagent (Roche Diagnostics, Basel, Switzerland) was used for RNA isolation. The isolated RNA was used for complementary (c)DNA synthesis. RNA $(1,000 \mathrm{ng})$ was reverse transcribed using Transcriptor First Strand cDNA Synthesis kit (Roche Diagnostics) according to manufacturer's protocol. The cDNA $(20 \mu \mathrm{l})$ prepared from total RNA was diluted with RNase-free water to $100 \mu 1$, and $5 \mu \mathrm{l}$ cDNA was directly analyzed using the LightCycler ${ }^{\circledR} 480$ II System (Roche Diagnostics).

$R T$-quantitative polymerase chain reaction ( $q P C R$ ). RT-qPCR was performed using TaqMan ${ }^{\circledR}$ Gene Expression Assays (Life Technologies; Thermo Fisher Scientific, Inc.) with the LightCycler ${ }^{\circledR} 480$ II System, and the amplified DNA was analyzed by the comparative $\Delta \Delta \mathrm{Cq}$ calculation (23) using $\beta$-actin as an endogenous control. The primer and probe sets for $\beta$-actin (Hs99999903_m1), metallothionein (MT)2 (Hs02379661_g1), MT1 (Hs00831826_s1), tumor protein p53 (TP53) (Hs01034249_m1), B-cell lymphoma (BCL)-2 associated X protein (BAX) (Hs00180269_m1), BCL-2 (Hs00608023_m1), vascular endothelial growth factor A 
A

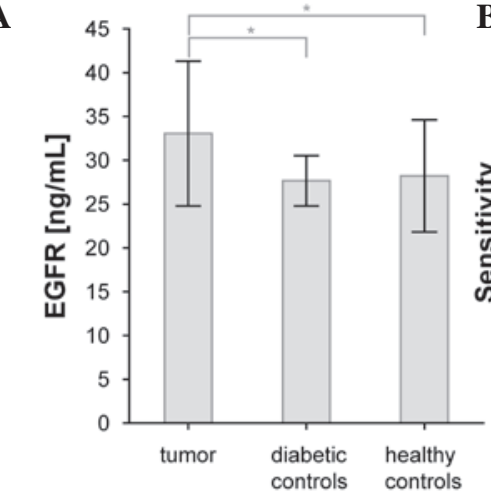

C

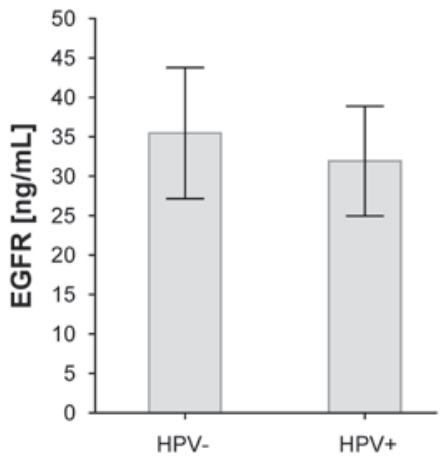

B
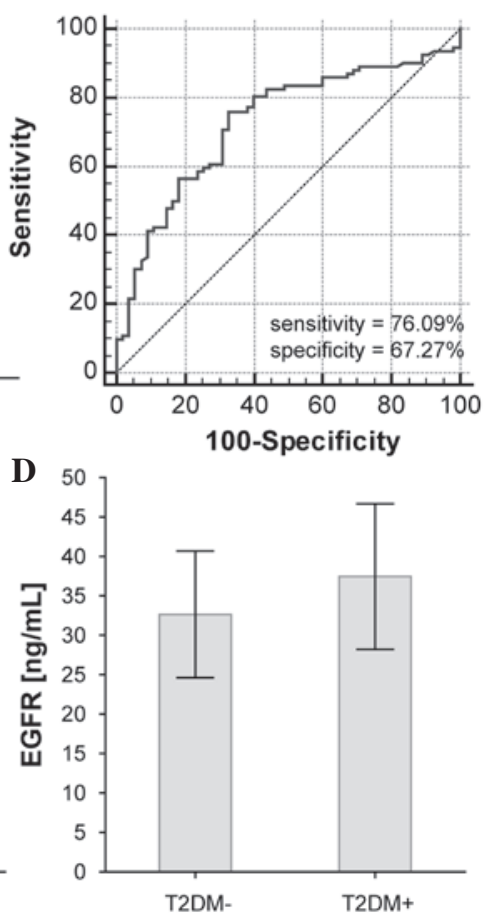

Figure 2. Plasmatic EGFR levels. (A) Plasma EGFR levels in head and neck squamous cell carcinoma patients and in two control groups ( $\mathrm{P}<0.05$ vs. controls). (B) Receiver operating characteristic curve analysis indicating the sensitivity and specificity of plasma EGFR detection. (C) Plasma EGFR levels in human papillomavirus-positive and -negative patients. (D) Plasma EGFR levels and type 2 diabetes mellitus status in patients. EGFR, epidermal growth factor receptor; T2DM, type 2 diabetes mellitus; HPV, human papillomavirus.

(VEGFA) (Hs00900055_m1), fms-related tyrosine kinase 1 (FLT1) (Hs01052961_m1), matrix metalloproteinase 2 (MMP2) (Hs01548727_m1), MMP9 (Hs00234579_m1), proto-oncogene c-Fos (FOS) (Hs00170630_m1), c-Jun (JUN) (Hs00277190_s1), marker of proliferation Ki-67 (MKI67) (Hs00606991_m1), EGF (Hs01099999_m1) and EGFR (Hs01076078_m1) were selected from TaqMan ${ }^{\circledR}$ Gene Expression Assays. RT-qPCR was performed under the following amplification conditions in a total volume of $20 \mu \mathrm{l}$ (5 $\mu \mathrm{l} \mathrm{cDNA}$, $10 \mu \mathrm{l} \mathrm{TaqMan}{ }^{\circledR}$ Gene Expression Master Mix, $4 \mu \mathrm{l}$ molecular-grade water and $1 \mu \mathrm{l}$ TaqMan Gene Expression Assay): Initial incubation, $50^{\circ} \mathrm{C}$ for $2 \mathrm{~min}$, followed by denaturation at $95^{\circ} \mathrm{C}$ for $10 \mathrm{~min}$ and then 45 cycles of $95^{\circ} \mathrm{C}$ for $15 \mathrm{sec}$ and $60^{\circ} \mathrm{C}$ for $1 \mathrm{~min}$.

Human papillomavirus (HPV) detection. The 142 bp-long sequence of the conservative major capsid protein L1 gene were amplified using general primers, GP5 and GP6, for non-specific identification of HPV-positive subjects. The PCR mixture from New England BioLabs, Inc. (Ipswich, MA, USA) contained PCR buffer (10 mM Tris HCl, pH 8.3, $50 \mathrm{mM}$ $\mathrm{KCl}$ and $2.5 \mathrm{mM} \mathrm{MgCl}$ ), $0.05 \mathrm{mM}$ of each deoxynucleotide, and $0.05 \mathrm{mM}$ of GP5 (5'-TTTGTTACTGTGGTAGATAC-3') and GP6 (5'-GAAAAATAAACTGTAAATCA-3') primers. The DNA amplification was performed during 40 cycles that included a denaturation step at $94^{\circ} \mathrm{C}$ for $30 \mathrm{sec}$, annealing at $45^{\circ} \mathrm{C}$ for $30 \mathrm{sec}$ and extension at $72^{\circ} \mathrm{C}$ for $30 \mathrm{sec}$.

As internal quality control of the isolated DNA, the $\beta$-actin gene $(600 \mathrm{bp})$ was amplified (forward primer 5'-CCTGAA CCCTAAGGCCAACC-3' and reverse primer 5'-GCAATG
CCTGGGTACATGGT-3'). Each PCR product was analyzed using electrophoresis on $1 \%$ agarose gels stained with ethidium bromide.

Data analysis. Differences between the two groups were calculated using the $t$-test. Survival analysis was conducted using Cox proportional hazard regression analysis with plasma EGFR levels as covariates. Receiver operating characteristic (ROC) curves were calculated using the DeLong methodology. Subsequently, Kaplan-Meier analysis was used with continuous data being divided into two groups as follows: Low expression (<mean values) and high expression $(\geq$ mean values) groups. The associations between the continuous variables were analyzed using Pearson's correlations. Unless noted otherwise, $\mathrm{P}<0.05$ was considered to indicate a statistically significant difference. Software STATISTICA 12 (StatSoft, Inc., Tulsa, OK, USA) and MedCalc 15.8 (MedCalc Software bvba, Ostend, Belgium) were used for analysis.

\section{Results}

Association between plasma levels of EGFR and HNSCC occurrence. No significant changes in EGFR plasma levels were observed between diabetic and healthy controls $(\mathrm{P}=0.690)$. However, there was a significant difference between EGFR plasma levels in HNSCC patients and in both control groups ( $\mathrm{P}=0.001$ and 0.005 , respectively) (Fig. 2A and Table II). If both control groups were assessed together, the statistical significance was $\mathrm{P}=0.0001$. ROC curve analysis identified a sensitivity of $76.09 \%$, a specificity of $67.27 \%$ and an area 
Table II. Plasma levels of EGFR and clinical characteristics in HNSCC patients.

\begin{tabular}{|c|c|c|c|}
\hline Factor & Status (number of cases) & $\begin{array}{c}\text { EGFR levels, } \mathrm{ng} / \mathrm{ml} \\
\text { mean } \pm \text { standard deviation }\end{array}$ & P-value \\
\hline \multirow[t]{3}{*}{ Cases vs. controls } & HNSCC patients (92) & $33.1 \pm 8.3$ & - \\
\hline & Healthy controls (29) & $28.2 \pm 6.4$ & 0.001 \\
\hline & Diabetic controls (26) & $27.7 \pm 2.9$ & 0.005 \\
\hline \multirow[t]{2}{*}{ Smoking } & Yes (59) & $31.8 \pm 7.7$ & 0.150 \\
\hline & No (28) & $34.5 \pm 8.5$ & - \\
\hline \multirow[t]{2}{*}{ Hypertension } & Yes (28) & $34.4 \pm 8.8$ & 0.380 \\
\hline & No (58) & $32.7 \pm 8.0$ & - \\
\hline \multirow[t]{2}{*}{ Diabetes mellitus } & Yes (10) & $37.4 \pm 9.2$ & 0.085 \\
\hline & No (76) & $32.6 \pm 8.0$ & - \\
\hline \multirow[t]{2}{*}{ TNM T-staging } & T1-2 (39) & $32.5 \pm 8.1$ & 0.580 \\
\hline & T3-4 (52) & $33.4 \pm 8.5$ & - \\
\hline \multirow[t]{2}{*}{ TNM N-staging } & $\mathrm{N}+(49)$ & $33.7 \pm 8.2$ & 0.430 \\
\hline & N- (42) & $32.3 \pm 8.5$ & - \\
\hline \multirow[t]{2}{*}{ TNM M-staging } & $\mathrm{M}+(5)$ & $31.3 \pm 8.1$ & 0.640 \\
\hline & M- (86) & $33.1 \pm 8.3$ & - \\
\hline \multirow[t]{2}{*}{ Tumor grade } & High (82) & $32.8 \pm 8.1$ & 0.270 \\
\hline & Low (6) & $36.8 \pm 12.3$ & - \\
\hline \multirow[t]{2}{*}{ HPV status } & $\mathrm{HPV}+(49)$ & $32.0 \pm 7.0$ & 0.084 \\
\hline & HPV- (18) & $35.5 \pm 8.3$ & - \\
\hline
\end{tabular}

EGFR, epidermal growth factor receptor; HNSCC, head and neck squamous cell carcinoma; TNM, tumor-node-metastasis; HPV, human papillomavirus.

A

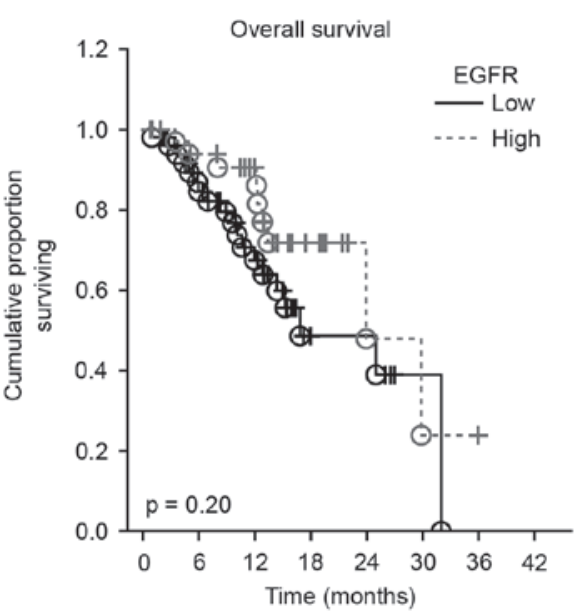

B

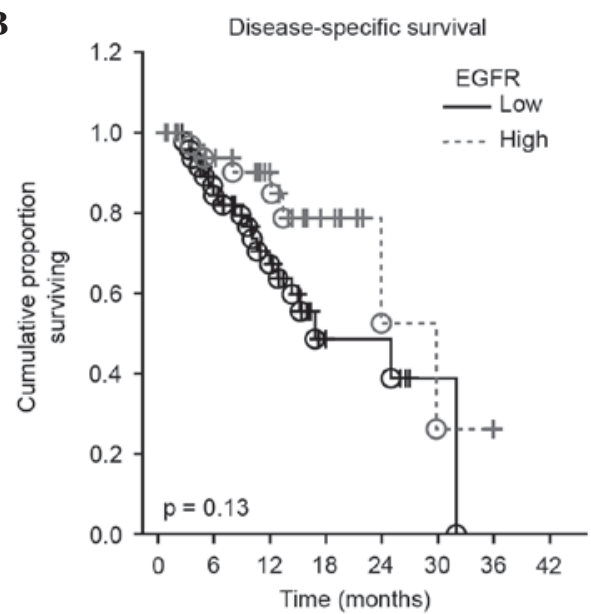

Figure 3. Survival analysis. (A) Kaplan-Meier overall survival analysis. (B) Disease-specific survival analysis. High/low EGFR indicate EGFR values above/below the mean EGFR values. P-value was calculated by Cox proportional hazard regression analysis. EGFR, epidermal growth factor receptor.

under the curve (AUC) of 0.727 for this comparison (Fig. 2B). Additional information about the patients and controls is contained in Table I.

Correlation between tumor gene expression and EGFR plasma levels. Correlations between plasma EGFR levels and expression of genes in tumor tissues of HNSCC patients were examined. There was no significant correlation between plasma EGFR levels and tumor tissue EGFR mRNA expression, and only a weak negative correlation with MMP9 mRNA was observed $(r=-0.21, P=0.040)$. Gene expression analyses of EGF, EGFR, MKI67, BCL-2, BAX, FOS, JUN, TP53, VEGFA, FLT1, MMP2, MMP9, MT1A and MT2A genes in HNSCC tumor tissue compared with tumor adjacent tissue and tonsillectomies have been published elsewhere (24).

Association between plasma levels of EGFR and clinicopathological characteristics. By examining the associations 
between plasma EGFR levels and clinicopathological characteristics of HNSCC patients, no significant association was identified for smoking habit, T2DM, hypertension, HPV infection, tumor stage, tumor grade, or lymph node or distant metastasis occurrence. However, the presence of HPV infection and T2DM in HNSCC patients had a borderline effect on the plasma EGFR levels (Table II and Fig. 2C and D).

Association between plasma levels of EGFR and disease-free and overall survival. The prognostic value of EGFR plasma levels on overall and disease-free survival was studied by Cox proportional hazard regression analysis and Kaplan-Meier curves. Survival analysis revealed no significant influence of plasmatic EGFR levels on overall or disease-specific survival in the present cohort of HNSCC patients [hazard ratio $(\mathrm{HR})=0.97 ; 95 \%$ confidence interval $(\mathrm{CI})=0.92-1.01$; $\mathrm{P}=0.200$, and $\mathrm{HR}=0.96 ; 95 \mathrm{CI}=0.91-1.01 ; \mathrm{P}=0.130$ for overall and disease-free survival, respectively] (Fig. 3).

\section{Discussion}

Numerous studies have shown that EGFR is overexpressed in HNSCC tumor tissue, but only few studies focused on soluble EGFR levels (24-26). There are contradictory studies on soluble EGFR levels, which could be either decreased or elevated in cancer patients compared with a healthy cohort. For example, Partanen et al reported that patients with asbestosis-induced lung cancer have elevated serum soluble EGFR ECD levels (27). Increased soluble EGFR ECD levels were also reported in the urine of patients with squamous cell carcinomas of the lung, head and neck (28), whereas patients with ovarian cancer had decreased levels of serum p110 EGFR compared with the normal population (29). In the present study, ELISA using antibodies against the L25-S645 region of EGFR was used to measure the levels of EGFR in plasma samples of HNSCC patients. Female patients were excluded from the present study due to possible gender-specific EGFR interactions with estrogen or androgen receptors (20-22). Significantly higher EGFR plasma levels were detected in HNSCC patients compared with the healthy cohort and the diabetic control group $(\mathrm{P}=0.001$ and 0.005 , respectively). This finding is in accordance with that of Perez-Torres et al (17), who suggested that the mechanism of proteolytic cleavage of EGFR and shedding of PI-sEGFR into the plasma may be activated in malignant cells that overexpress the full-length receptor. The cleavage of EGFR probably occurs in the transmembrane domain between G625 and M626 (17). In HNSCC patients, EGFR expression is supposed to be higher in tumor tissues compared with tonsillectomy samples and tumor-adjacent tissues (24). Furthermore, the release of two soluble EGFR isoforms within the exosomes is activated by EGF (17), which is highly produced by HNSCC tumor-adjacent tissues (24).

No significant changes in EGFR plasma levels were observed between diabetic and healthy controls, which is not in accordance with the Vairaktaris et al hypothesis that diabetes suppresses the expression of EGFR (19). However, a slight change on the borderline of statistical significance was observed between HNSCC patients with or without diabetes $(\mathrm{P}=0.085)$, while HNSCC patients with diabetes tended to have higher EGFR plasma levels. Borderline changes in EGFR plasma levels were also noticed between the HPV-positive and HPV-negative groups of HNSCC patients (slightly higher levels of plasmatic EGFR were detected in the HPV-negative cohort), although these changes were not significant.

Survival analysis revealed no significant influence of the plasmatic EGFR levels on overall and disease-specific survival in the present cohort of HNSCC patients. By contrast, Ye et al demonstrated that non-small-cell lung cancer patients with lower plasma EGFR concentrations $(<27.24 \mathrm{ng} / \mathrm{ml})$ had a significantly shorter overall survival compared with patients who had higher plasma EGFR concentrations $(\geq 27.24 \mathrm{ng} / \mathrm{ml})$ (18.2 vs. 33.4 months, $\mathrm{P}=0.021$ ) (30).

In conclusion, EGFR plasma levels appear to be a relatively promising diagnostic, but poor prognostic, HNSCC marker. However, further studies are required to determine the clinical value of plasmatic EGFR levels in HNSCC patients. The next important step in soluble EGFR research should be a precise distinction between 110-kDa PI-sEGFR originating from full-length EGFR protein cleavage and EGFR isoforms originating from alternative splicing of EGFR gene transcripts. These EGFR isoforms could readily have slightly different functions. For example, 110-kDa PI-sEGFR originating from full-length EGFR protein cleavage could reflect the presence of malignant cells that overexpress the full-length receptor (17) or a necrotic disintegration of tumor cells. Such form of soluble EGFR was probably originally involved in a proliferative signaling pathway, and could be marker of poor prognosis, while the soluble EGFR isoform originating from alternative splicing was probably not an activator of these proliferative signaling pathways due to the missing intracellular domain, and could exhibit a high affinity binding for EGF, which should result in decreased proliferative signaling and better prognosis.

\section{Acknowledgements}

The present study was supported by the Ministry of Health of the Czech Republic (Prague, Czech Republic; grant no. IGA MZ NT 14337-3/2013) and by Specific University Research Grants (grant nos. MUNI/A/1365/2015 and MUNI/A/1426/2015) provided by the Ministry of Education, Youth and Sports of the Czech Republic (Prague, Czech Republic) in 2016 and by Czech Science Foundation (GACR GA16-12454S).

\section{References}

1. Albitar L, Pickett G, Morgan M, Wilken JA, Maihle NJ and Leslie KK: EGFR isoforms and gene regulation in human endometrial cancer cells. Mol Cancer 9: 166, 2010.

2. Ullrich A, Coussens L, Hayflick JS, Dull TJ, Gray A, Tam AW, Lee J, Yarden Y, Libermann TA, Schlessinger J, et al: Human epidermal growth-factor receptor cDNA sequence and aberrant expression of the amplified gene in A431 epidermoid carcinoma-cells. Nature 309: 418-425, 1984.

3. Ciardiello F and Tortora G: Epidermal growth factor receptor (EGFR) as a target in cancer therapy: Understanding the role of receptor expression and other molecular determinants that could influence the response to anti-EGFR drugs. Eur J Cancer 39: 1348-1354, 2003

4. Psyrri A, Seiwert TY and Jimeno A: Molecular pathways in head and neck cancer: EGFR, PI3K, and more. Am Soc Clin Oncol Educ Book: 246-255, 2013.

5. Sartor CI: Biological modifiers as potential radiosensitizers: Targeting the epidermal growth factor receptor family. Semin Oncol 27 (6 Suppl 11): S15-S20; discussion 92-100, 2000. 
6. Woodburn JR: The epidermal growth factor receptor and its inhibition in cancer therapy. Pharmacol Ther 82: 241-250, 1999.

7. Nicholson RI, Gee JM and Harper ME: EGFR and cancer prognosis. Eur J Cancer 37 (Suppl 4): S9-S15, 2001.

8. Salomon DS, Brandt R, Ciardiello F and Normanno N: Epidermal growth factor-related peptides and their receptors in human malignancies. Crit Rev Oncol Hematol 19: 183-232, 1995.

9. Rubin Grandis J, Melhem MF, Gooding WE, Day R, Holst VA, Wagener MM, Drenning SD and Tweardy DJ: Levels of TGF-alpha and EGFR protein in head and neck squamous cell carcinoma and patient survival. J Natl Cancer Inst 90: 824-832, 1998.

10. Box C, Rogers SJ, Mendiola M and Eccles SA: Tumour-microenvironmental interactions: Paths to progression and targets for treatment. Semin Cancer Biol 20: 128-138, 2010.

11. Zuo JH, Zhu W, Li MY, Li XH, Yi H, Zeng GQ, Wan XX, He QY, $\mathrm{Li} \mathrm{JH}, \mathrm{Qu} \mathrm{JQ}$, et al: Activation of EGFR promotes squamous carcinoma SCC10A cell migration and invasion via inducing EMT-Like phenotype change and MMP-9-mediated degradation of E-cadherin. J Cell Biochem 112: 2508-2517, 2011.

12. Holz C, Niehr F, Boyko M, Hristozova T, Distel L, Budach V and Tinhofer I: Epithelial-mesenchymal-transition induced by EGFR activation interferes with cell migration and response to irradiation and cetuximab in head and neck cancer cells. Radiother Oncol 101: 158-164, 2011.

13. Wang SJ and Bourguignon LY: Hyaluronan and the interaction between CD44 and epidermal growth factor receptor in oncogenic signaling and chemotherapy resistance in head and neck cancer. Arch Otolaryngol Head Neck Surg 132: 771-778, 2006

14. Hunts JH, Shimizu N, Yamamoto T, Toyoshima K, Merlino GT, $\mathrm{Xu}$ YH and Pastan I: Translocation chromosome 7 of A431 cells contains amplification and rearrangement of EGF receptor gene responsible for production of variant mRNA. Somat Cell Mol Genet 11: 477-484, 1985.

15. Kulasinghe A, Perry C, Jovanovic L, Nelson C and Punyadeera C: Circulating tumour cells in metastatic head and neck cancers. Int J Cancer 136: 2515-2523, 2015

16. Ancot F, Foveau B, Lefebvre J, Leroy C and Tulasne D Proteolytic cleavages give receptor tyrosine kinases the gift of ubiquity. Oncogene 28: 2185-2195, 2009.

17. Perez-Torres M, Valle BL, Maihle NJ, Negron-Vega L, Nieves-Alicea R and Cora EM: Shedding of epidermal growth factor receptor is a regulated process that occurs with overexpression in malignant cells. Exp Cell Res 314: 2907-2918, 2008.

18. Sanderson MP, Keller S, Alonso A, Riedle S, Dempsey PJ and Altevogt P: Generation of novel, secreted epidermal growth factor receptor (EGFR/ErbB1) isoforms via metal loprotease-dependent ectodomain shedding and exosome secretion. J Cell Biochem 103: 1783-1797, 2008.
19. Vairaktaris E, Goutzanis L, Yapijakis C, Vassiliou S, Spyridonidou S, Vylliotis A, Nkenke E, Lazaris AC, Strantzias P and Patsouris E: Diabetes enhances the expression of $\mathrm{H}$-ras and suppresses the expression of EGFR leading to increased cell proliferation. Histol Histopathol 24: 531-539, 2009.

20. Britton DJ, Hutcheson IR, Knowlden JM, Barrow D, Giles M, McClelland RA, Gee JM and Nicholson RI: Bidirectional cross talk between ERalpha and EGFR signalling pathways regulates tamoxifen-resistant growth. Breast Cancer Res Treat 96: 131-146, 2006.

21. Levin ER: Bidirectional signaling between the estrogen receptor and the epidermal growth factor receptor. Mol Endocrinol 17: 309-317, 2003

22. Bonaccorsi L, Muratori A, Carloni V, Marchiani S, Formigli L, Forti $\mathrm{G}$ and Baldi E: The androgen receptor associates with the epidermal growth factor receptor in androgen-sensitive prostate cancer cells. Steroids 69: 549-552, 2004.

23. Livak KJ and Schmittgen TD: Analysis of relative gene expression data using real-time quantitative PCR and the 2(-Delta Delta C(T)) Method. Methods 25: 402-408, 2001.

24. Raudenska M, Sztalmachova M, Gumulec J, Fojtu M, Polanska H, Balvan J, Feith M, Binkova H, Horakova Z, Kostrica R et al: Prognostic significance of the tumour-adjacent tissue in head and neck cancers. Tumour Biol 36: 9929-9939, 2015.

25. Polanska H, Raudenska M, Gumulec J, Sztalmachova M Adam V, Kizek R and Masarik M: Clinical significance of head and neck squamous cell cancer biomarkers. Oral Oncol 50: 168-177, 2014.

26. Grandis JR and Tweardy DJ: Elevated levels of transforming growth-factor-alpha and epidermal growth-factor receptor messenger RNA are early markers of carcinogenesis in head and neck-cancer. Cancer Res 53: 3579-3584, 1993.

27. Partanen R, Hemminki K, Koskinen H, Luo JC, Carney WP and Brandtrauf PW: The detection of increased amounts of the extracellular domain of the epidermal growth-factor receptor in serum during carcinogenesis in asbestosis patients. J Occup Med 36: 1324-1328, 1994.

28. Witters LM, Curley EM, Kumar R, Chinchilli VM, Harvey JP Crebbin V, Harvey HA and Lipton A: Epidermal growth factor receptor ectodomain in the urine of patients with squamous cell carcinoma. Clin Cancer Res 1: 551-557, 1995.

29. Carney WP: Circulating oncoproteins HER2/neu, EGFR and CAIX (MN) as novel cancer biomarkers. Expert Rev Mol Diagn 7: 309-319, 2007

30. Ye P, Zhao J, Wang S and Kong FM: The plasma level of soluble epidermal growth factor Receptor (EGFR) and overall survival (OS) in non-small-cell lung cancer (NSCLC) patients. Annual Meeting of the American Society of Clinical Oncology (ASCO). J Clin Oncol 33: e19091, 2015. 